\title{
DESPACHO ADUANEIRO DE IMPORTAÇÃO EM ANGOLA: OPORTUNIDADES E DESAFIOS
}

DOI: http://dx.doi.org/10.18616/pers07

Neir Alberto Lucinga Chitén - Unesc

E-mail: neyrclaiton@gmail.com

Júlio Cesar Zilli - Unesc

E-mail: zilli42@hotmail.com 


\section{INTRODUÇÃO}

O dinamismo do comércio internacional proporciona novos desafios para as empresas importadoras e exportadoras, por meio das diversas alterações econômicas, logísticas, documentais e de infraestrutura. Esse cenário coloca as empresas em uma constante flexibilidade para suprir os desafios advindos da globalização.

Diante do crescimento das relações internacionais, as empresas estão cada vez mais próximas umas das outras, trocando benefícios e serviços, visando aumentar a sua lucratividade. Com o decorrer dos anos, a internacionalização passou a ser uma alternativa viável de expansão de mercado, além de ser fonte de obtenção de lucros, possibilita verificar as competências, estabelecendo, então, alianças estratégias importantes para o desenvolvimento (MINERVINI, 2001).

A ascensão das relações internacionais e o fluxo contínuo de bens e serviços em mercados multiculturais fez com que os países se reorganizassem e se readequassem, principalmente, no âmbito da logística internacional, uma vez que sua infraestrutura estava inadequada diante dos seus concorrentes no mercado global (MARINI, 2010).

Nesse contexto, é possível verificar que a pauta das importações de Angola é concentrada, principalmente, em bens industrializados e a exportação em combustíveis, necessitando de: "[...] eficácia no fluxo de importações e exportações, com destaque para o despacho aduaneiro de importação, por ser um procedimento fiscal pelo qual todas as mercadorias passam necessariamente, a fim de serem nacionalizadas" (ZILLI; LINO; DAL TOÉ, 2013, p. 2).

Assim, o presente estudo tem por objetivo identificar as barreiras internas e externas das empresas importadoras de Angola no processo de nacionalização das mercadorias.

Inicialmente, o estudo apresenta uma contextualização sobre a participação de Angola no mercado externo, com ênfase na evolução do comércio internacional, parceiros comerciais, indicadores econômicos e principais produtos exportados e importados, bem como o fluxo do processo de despacho aduaneiro de importação em Angola.

Em seguida, apresentam-se os resultados da pesquisa, as considerações finais e, por fim, as referências. 


\section{ANGOLA NO MERCADO INTERNACIONAL}

Angola esta situada no continente africano, especificamente na África Austral, fazendo fronteira a Nordeste com a República Democrática do Congo, a Leste com a Zâmbia, ao Sul com a Namíbia e a Oeste com o Oceano Atlântico. Foi uma colônia portuguesa, tornando-se independente em 1975, conforme dados do Ministério do Comércio - MINCO (2012).

Sua extensão geográfica é de $1.246 .700 \mathrm{Km}^{2}$, com uma distribuição territorial constituída por 18 províncias, com um nível populacional de 20,8 milhões de habitantes, sendo Luanda a maior cidade e o centro administrativo. Angola é o 23 o maior país em extensão, com diversidade de recursos naturais, tais como petróleo, diamantes, minério de ferro, fosfatos, cobre, ouro, bauxita e urânio (DOWBOR, 2012; MRE, 2014).

De acordo com o Ministério das Relações Exteriores - MRE (2014), o idioma oficial é o Português e a moeda é o Kwanza. Os dados registram que 70,1\% da população é alfabetizada e com expectativa de vida de 51,5 anos. No ranking do Índice de Desenvolvimento Humano (IDH) de 2012, o país está na $148^{\circ}$ posição. Dentre os principais indicadores socioeconômicos de Angola, o MRE divulgou em março de 2015, uma série de cinco anos, a partir de 2012 e uma projeção para 2016, demonstrado na tabela 1.

Tabela 1 - Indicadores socioeconômicos de Angola

\begin{tabular}{lrrrrr}
\hline \multicolumn{1}{c}{ INDICADORES } & $\mathbf{2 0 1 2}$ & $\mathbf{2 0 1 3}$ & $\mathbf{2 0 1 4}$ & $\mathbf{2 0 1 5}$ & \multicolumn{1}{c}{$\mathbf{2 0 1 6}$} \\
\hline Crescimento real (\%) & $5,16 \%$ & $6,80 \%$ & $3,94 \%$ & $5,92 \%$ & $6,16 \%$ \\
\hline PIB nominal (US\$ bilhões) & 115,34 & 124,18 & 131,41 & 141,76 & 152,02 \\
\hline PIB nominal "per capita" (US\$) & 5.706 & 5.964 & 6.128 & 6.418 & 6.682 \\
\hline PIB PPP (US\$ bilhões) & 153,25 & 166,11 & 175,54 & 189,36 & 204,81 \\
\hline PIB PPP "per capita" (US\$) & 7.581 & 7.978 & 8.186 & 8.573 & 9.003 \\
\hline População (milhões de habitantes) & 20,21 & 20,82 & 21,44 & 22,09 & 22,75 \\
\hline Inflação (\%) & $9,04 \%$ & $7,69 \%$ & $7,36 \%$ & $7,20 \%$ & $6,90 \%$ \\
\hline Saldo em transações correntes (US\$ bilhões) & 13,42 & 6,81 & 5,4 & 2,87 & $-0,17$ \\
\hline Dívida externa (US\$ bilhões) & 20,11 & 24 & 27,13 & 30,68 & 34,69 \\
\hline Câmbio (Kz/US\$) & 95,83 & 97,56 & 101,15 & 103,6 & 104,02 \\
\hline
\end{tabular}

Fonte: Adaptado de MRE (2015, p. 2).

De acordo com o MRE (BRASIL, 2014), o desenvolvimento da economia Angolana tem sido destaque no comércio mundial, decorrente de seu crescimento, ocupando a 57ạ posição no mercado global e a 46ạ posição de exportador e 
74a de importador. Nos anos de 2004 a 2008 a evolução do comércio exterior angolana apresentou crescimento significativo para as vendas e compras internacionais. Porém, entre os anos de 2008 a 2009, ocorreu um desaquecimento, resultado principalmente da crise econômica mundial no período, conforme pode ser observado na figura 1.

Denota-se um crescimento das exportações nos anos subsequentes, pois o comércio exterior de Angola apresentou em 2013 um: "[...] crescimento de 61,3\% em relação a 2009 , de US\$ 57,7 bilhões para US\$ 93,1 bilhões. O saldo da balança comercial, superavitário em todo o quinquênio analisado, apresentou saldo positivo de US\$ 48,9 bilhões em 2013" (BRASIL, MRE, 2014, p. 5).

Com relação à categoria dos produtos comercializados na exportação, predominam os combustíveis (óleos brutos de petróleo). No ano de 2013 estes produtos representaram $97 \%$ da pauta de comercialização, com destaque também para as embarcações flutuantes (barcos, transatlânticos e rebocadores) com 1,7\%; e ouro e pedras preciosas (diamantes) com 0,9\% (BRASIL, MRE, 2014).

Figura 1 - Evolução do comércio exterior de Angola

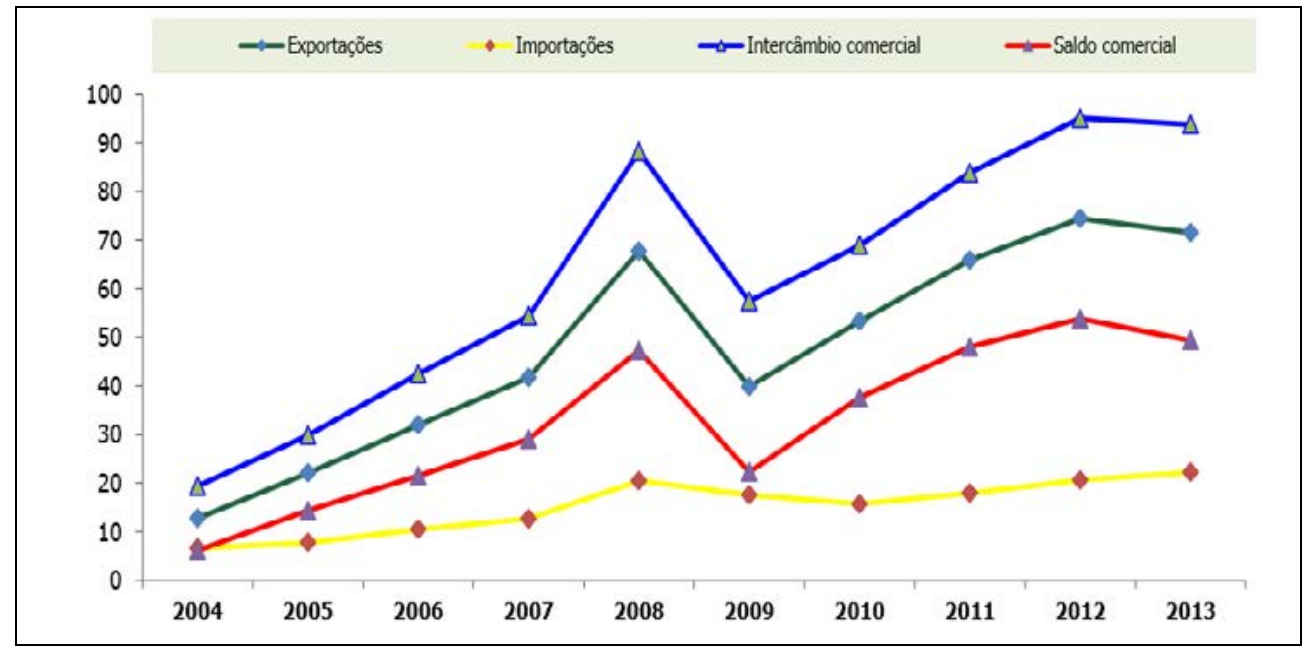

Fonte: $\operatorname{MRE}(2015$, p. 3).

Na pauta importadora, concentram-se os bens industrializados, tais como: máquinas mecânicas (torneiras e válvulas, partes de máquinas, máquinas e apareIhos com função própria, centrifugadores) representando $16,1 \%$ do total; máquinas elétricas (grupos eletrogêneos e conversores rotativos elétricos, fios e cabos, aparelhos para telefonia) com 7,7\%; automóveis (carros de passeio, caminhões, 
motocicletas) com 7,5\%; embarcações flutuantes (barcos-faróis, barcos-bombas, dragas, guindastes flutuantes; docas flutuantes; plataformas de perfuração ou de exploração) com $6,8 \%$; obras de ferro ou aço $(5,8 \%)$; combustíveis (óleos de petróleo refinado) com 5,1\%; e carnes (de frango e bovina) com 3,9\% (BRASIL, MRE, 2014). Esses produtos são comercializados para diversos lugares no globo, conforme é apresentado na tabela 2 .

Tabela 2 - Direção das exportações e importações de Angola

\begin{tabular}{|c|c|c|c|c|c|}
\hline EXPORTAÇÃO & 2013 & $\begin{array}{c}\text { PART. \% NO } \\
\text { TOTAL } \\
\end{array}$ & IMPORTAÇÃO & 2013 & $\begin{array}{l}\text { PART. \% NO } \\
\text { TOTAL }\end{array}$ \\
\hline China & 31,97 & 44,70 & Portugal & 4,13 & 18,60 \\
\hline EUA & 8,93 & 12,50 & China & 3,96 & 17,80 \\
\hline Índia & 6,80 & 9,50 & Estados Unidos & 1,45 & 6,50 \\
\hline Taiwan & 3,86 & 5,40 & Brasil & 1,27 & 5,70 \\
\hline Portugal & 3,49 & 4,90 & Coreia do Sul & 1,24 & 5,60 \\
\hline Espanha & 2,88 & 4,00 & África do Sul & 1 & 4,50 \\
\hline África do Sul & 1,96 & 2,70 & Congo & 0,89 & 4,00 \\
\hline Canadá & 1,51 & 2,10 & Reino Unido & 0,86 & 3,90 \\
\hline Países Baixos & 1,42 & 2,00 & França & 0,61 & 2,80 \\
\hline Congo & 1,26 & 1,80 & Bélgica & 0,59 & 2,70 \\
\hline ... Brasil & 0,73 & 1,00 & & & \\
\hline SUB TOTAL & 64,80 & 90,60 & SUB TOTAL & 16,02 & $\mathbf{7 2 , 0 0}$ \\
\hline OUTROS PAÍSES & 6,75 & $\mathbf{9 , 4 0}$ & OUTROS PAÍSES & 6,22 & 28,00 \\
\hline TOTAL & 71,55 & 100,00 & TOTAL & 22,23 & 100,00 \\
\hline
\end{tabular}

Fonte: Elaborado a partir de dados do MRE (2015).

Nas vendas externas, denota-se que o mercado chinês é o grande parceiro comercial de Angola, representando 44,70\% das exportações, seguido dos Estados Unidos da América (EUA) com 12,50\% e Índia com 9,50\%. Portugal e a China são os grandes fornecedores de produtos acabados ao mercado angolano, representando juntos $36,40 \%$ das importações.

No entanto, as exportações de Angola para o mercado brasileiro representaram em 2013, apenas 0,73\% do total. Entretanto, o Brasil está entre os grandes fornecedores de produtos para Angola, ficando atrás apenas dos EUA.

De acordo com o MRE (2014), a balança comercial brasileira com o mercado angolano é pautada, principalmente, na exportação brasileira de carnes $(27,2 \%)$, açúcar $(14,7 \%)$, automóveis $(8,9 \%)$, preparações de carne $(5,8 \%)$ e máquinas mecânicas (4,4\%). Na importação, a relação comercial é basicamente pautada na comercialização por parte de Angola de combustíveis (100\%). 
A evolução do intercâmbio comercial do Brasil com Angola pode ser observada na figura 2.

Figura 2 - Evolução intercâmbio comercial Brasil x Angola

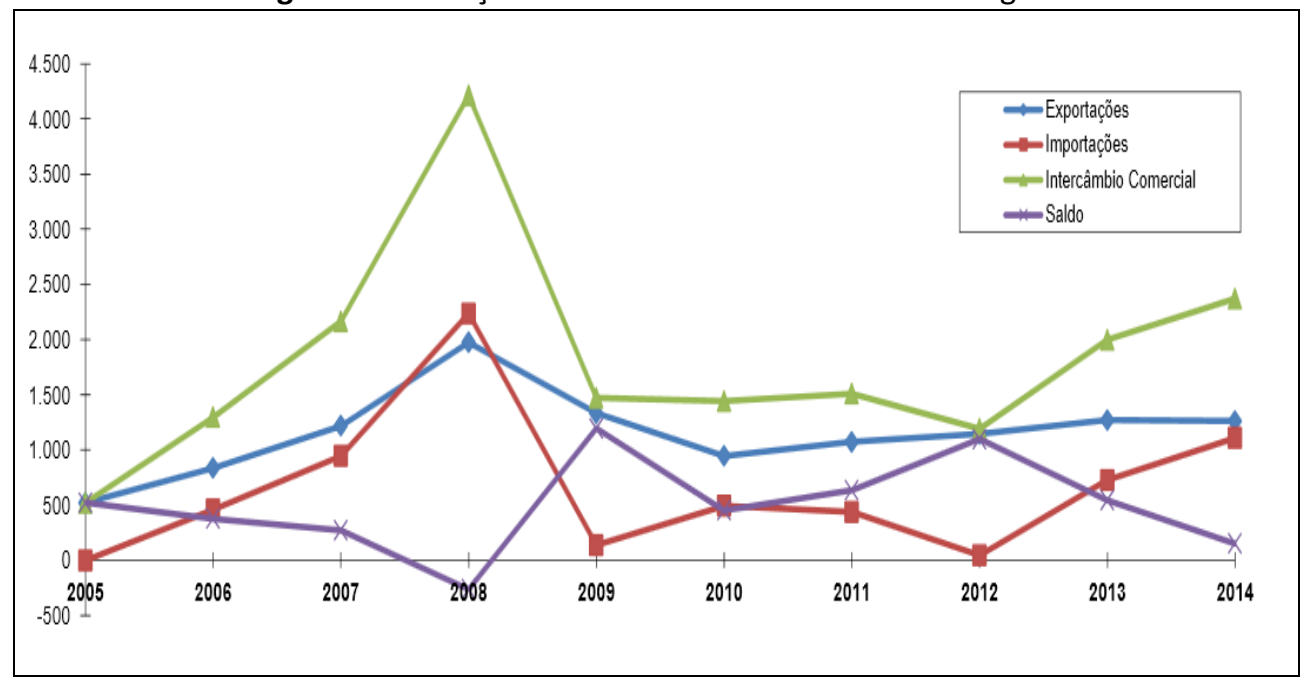

Fonte: MRE (2015, p.8).

Como $42 \%$ parceiro comercial brasileiro e representando $0,4 \%$ do comercio exterior brasileiro em 2013, o intercâmbio comercial entre o Brasil e Angola cresceu 35,9\%, ou seja, de US\$1,47 bilhão para US\$1,99 bilhão, no período de 2009 a 2013. Vale destacar que as exportações brasileiras recuaram $4,6 \%$ e as importações aumentaram em 427,6\% (MRE, 2014). Como pode ser observado na figura 1, o saldo comercial é favorável à economia brasileira, registrando em 2013 um superávit de US\$ 544 milhões.

\section{DESPACHO ADUANEIRO DE IMPORTAÇÃO}

No âmbito das importações, para a Receita Federal do Brasil - RFB (BRASIL, 2015 , p. 1), o despacho aduaneiro: “[...] é o procedimento mediante o qual é verificada a exatidão dos dados declarados pelo importador em relação às mercadorias importadas, aos documentos apresentados e à legislação específica, com vistas ao seu desembaraço aduaneiro". O quadro 1 apresenta uma síntese do processo de despacho aduaneiro de importação em Angola. 
Quadro 1 - Síntese do fluxo de despacho aduaneiro de importação em Angola

\begin{tabular}{|c|c|}
\hline DESPACHO ADUANEIRO & PROCEDIMENTOS \\
\hline Licenciamento da importação & Emitido pelo Sistema de Comércio Exterior (SICOEX). \\
\hline Inspeção pré-embarque & Empresas inspetoras (Certificado de Inspeção Pré-Embarque). \\
\hline Manifesto da carga & $\begin{array}{l}\text { Armador submete eletronicamente o manifesto da carga a alfândega via } \\
\text { Sistema de Gestão Eletrônica de Manifesto de Carga (SIGEMAC). }\end{array}$ \\
\hline Presença de carga & $\begin{array}{l}\text { Declaração sumária dos meios de transporte emitida pelo agente de } \\
\text { navegação. }\end{array}$ \\
\hline $\begin{array}{l}\text { Registro da Declaração Aduaneira de } \\
\text { Importação - DAI }\end{array}$ & $\begin{array}{l}\text { Despachante efetua a entrega física do Documento Único (DU) e demais } \\
\text { documentos a área de aceitação da SRAL ou submete via Sistema } \\
\text { Integrado Aduaneiro (SIADU). }\end{array}$ \\
\hline Seleção parametrização & O sistema TIMS seleciona o perfil para a mercadoria. \\
\hline $\begin{array}{l}\text { Pagamento dos direitos de } \\
\text { importação }\end{array}$ & $\begin{array}{l}\text { A SRAL emite uma nota de liquidação, a ser liquidada pelo importador } \\
\text { em alguma instituição bancária. }\end{array}$ \\
\hline Desembaraço da mercadoria & Após a liquidação da dívida é emitida a nota de desalfandegamento. \\
\hline Carregamento da mercadoria & $\begin{array}{l}\text { Importador efetua o pagamento das taxas EP14 e EP17 e retira a } \\
\text { mercadoria do porto entre } 5 \text { a } 10 \text { dias. }\end{array}$ \\
\hline
\end{tabular}

Fonte: Adaptado de Zilli, Lino e Dal Toé (2013, p. 10-11).

\section{PROCEDIMENTOS METODOLÓGICOS}

Esta pesquisa, quanto aos fins de investigação, classifica-se como descritiva, pois de acordo com Alves (2006), procura descrever uma população ou um fenômeno, determinando a relações entre as variáveis. Nesse sentido, a convergência com o estudo se justifica, uma vez que procurou identificar os desafios encontrados pelas empresas importadoras de Angola no processo de nacionalização das mercadorias.

Em relação aos meios de investigação, é uma pesquisa bibliográfica e de campo (VERGARA, 2009). A pesquisa bibliográfica baseou-se, principalmente, em publicações do Ministério das Relações Exteriores (MRE) do Brasil e Angola, bem como em dissertações, monografias, jornais, sites e boletins estatísticos.

A partir de uma população de 100 empresas importadoras localizadas em Luanda/Angola e devidamente registradas no Conselho Nacional dos Carregadores de Angola (CNCA), opta-se por uma amostra intencional por acessibilidade, composta por 17 empresas que, efetivamente, participaram da pesquisa.

Para a coleta dos dados, foi aplicado um questionário via Google Docs junto aos gerentes de importação das empresas angolanas, contemplando: i) perfil empresarial; ii) perfil logístico; iii) perfil das barreiras internas e externas; e v) perspectivas de fomento as importações. De acordo com Vergara (2009), os questionários podem ser aplicados de forma impressa ou digital, permitindo a utilização 
de perguntas abertas, estruturadas ou fechadas. Roesch (2007, p. 142) reforça que "[...] é um instrumento que busca mensurar alguma coisa".

Por fim, para a interpretação dos dados foi utilizada uma abordagem essencialmente qualitativa (CERVO; BERVIAN; SILVA, 2007), sem a presença de um tratamento estatístico, como médias ponderadas, que justificassem uma abordagem quantitativa.

\section{RESULTADOS E DISCUSSÃO}

Nesta etapa da pesquisa, de acordo com o quadro 2, foi traçado um perfil das empresas importadoras.

Quadro 2 - Perfil das empresas importadoras

\begin{tabular}{|c|c|c|c|c|c|c|c|c|}
\hline \multirow{2}{*}{ SETOR } & \multirow{2}{*}{ PORTE } & \multirow{2}{*}{ LOCALIZAC̣ÃO } & \multirow{2}{*}{ CAPITAL } & \multirow{2}{*}{ TEMPO } & \multirow{2}{*}{$\%$} & \multirow{2}{*}{ FORMA } & \multicolumn{2}{|c|}{ TOTAL } \\
\hline & & & & & & & $\mathbf{F}$ & $\%$ \\
\hline \multirow{6}{*}{ Alimenticio } & \multirow{3}{*}{ Grande } & \multirow{2}{*}{ Luanda } & Nacional & \multirow{2}{*}{10 a 15 anos } & \multirow{2}{*}{ Acima $50 \%$} & \multirow{2}{*}{ Direta } & \multirow{2}{*}{2} & \multirow{6}{*}{35,3} \\
\hline & & & Misto & & & & & \\
\hline & & Benguela & Misto & 10 a 15 anos & Acima $50 \%$ & Direta & 1 & \\
\hline & \multirow{2}{*}{ Médio } & \multirow{2}{*}{ Luanda } & Nacional & 10 a 15 anos & 30 a $40 \%$ & Indireta & \multirow{2}{*}{2} & \\
\hline & & & Estrangeiro & 5 a 10 anos & 40 a $50 \%$ & Direta & & \\
\hline & Pequena & Luanda & Nacional & 5 a 10 anos & 40 a $50 \%$ & Direta & 1 & \\
\hline Cerâmico & Médio & Benguela & Misto & 20 a 25 anos & Acima $50 \%$ & Direta & 1 & 5,88 \\
\hline \multirow{2}{*}{ Máq. e Equip. } & Pequena & Cabinda & \multirow{2}{*}{ Nacional } & \multirow{2}{*}{5 a 10 anos } & \multirow{2}{*}{30 a $40 \%$} & \multirow{2}{*}{ Direta } & \multirow{2}{*}{2} & \multirow{2}{*}{11,76} \\
\hline & Médio & Benguela & & & & & & \\
\hline Metalúrgico & Médio & Benguela & Nacional & Acima de 25 anos & Acima de $50 \%$ & Direta & 1 & 5,88 \\
\hline Plástico & Médio & Cabinda & Nacional & 20 a 25 anos & 40 a $50 \%$ & Direta & 1 & 5,88 \\
\hline Vestuário & Médio & Luanda & Nacional & 20 a 25 anos & $25 \%$ a $30 \%$ & Indireta & 1 & 5,88 \\
\hline Quimico & Médio & Luanda & Misto & 10 a 15 anos & $25 \%$ a $30 \%$ & Indireta & 1 & 5,88 \\
\hline Autopeça & Pequena & Luanda & Misto & 10 a 15 anos & $25 \%$ a $30 \%$ & Indireta & 1 & 5,88 \\
\hline Concessionária & Pequena & Luanda & Nacional & 5 a 10 anos & Acima $50 \%$ & Direta & 1 & 5,88 \\
\hline Construção Civil & Grande & Luanda & Nacional & Acima de 25 anos & Acima $50 \%$ & Direta & 1 & 5,89 \\
\hline Elétrico & Médio & Cabinda & Misto & 20 a 25 anos & Acima $50 \%$ & Direta & 1 & 5,89 \\
\hline TOTAL & & & & & & & 17 & 100,00 \\
\hline
\end{tabular}

Fonte: Elaborado pelos autores a partir dos resultados da pesquisa.

Observando a composição do quadro 2, pode-se verificar a predominância do setor alimentício, representando $35,3 \%$, bem como o porte médio das empresas importadoras.

No que tange à localização, Luanda possui a maior representatividade, pois de acordo com Dilolwa (2000), a deflagração do conflito civil favoreceu um grande êxodo populacional em direção à capital. Todas as empresas apresentam um capital predominantemente nacional, com expressiva participação da prática importadora, experiência nas relações comerciais e a comercialização é feita, essencialmente, na forma direta. 
O perfil logístico, destacado no quadro 3, procurou apresentar de forma sistematizada o principal porto utilizado para a nacionalização e acondicionamento das mercadorias, o modal e o Incoterm utilizado.

O Porto de Luanda, localizado na capital de Angola, caracteriza-se como um grande porto nacional para a liberação das mercadorias importadas $(58,83 \%)$, seguido com menor destaque os portos de Namibe e Cabinda.

Quadro 3 - Perfil logístico das empresas importadoras

\begin{tabular}{|l|l|r|r|}
\hline \multirow{2}{*}{ QUESTÃo } & \multicolumn{2}{|c|}{ PORTO } & \multicolumn{2}{|c|}{ TOTAL } \\
\cline { 2 - 4 } & & \multicolumn{1}{|c|}{ F } & \multicolumn{1}{c|}{$\%$} \\
\hline \multirow{4}{*}{ Porto } & Luanda & 10 & 58,83 \\
\cline { 2 - 4 } & Lobito & 4 & 23,53 \\
\cline { 2 - 4 } & Namibe & 2 & 11,76 \\
\cline { 2 - 5 } & Cabinda & 17 & 5,88 \\
\hline Acondicionamento & Container & 17 & 100,00 \\
\hline Modal & Marítimo & 14 & 100,00 \\
\hline \multirow{3}{*}{ Incoterm } & CIF & 2 & 82,36 \\
\cline { 2 - 5 } & CFR & 1 & 11,76 \\
\cline { 2 - 5 } & FOB & & 5,88 \\
\hline
\end{tabular}

Fonte: Elaborado pelos autores a partir dos resultados da pesquisa.

De acordo com o Consulado de Angola (BRASIL, 2014), no Porto de Luanda transitam mais 70\% das importações e exportações angolanas. Em decorrência dessa concentração na movimentação de mercadorias e por ineficiência portuária, os congestionamentos são constantes. A Revista de Marinha (2009) afirma que o porto vive uma situação de congestionamento devido à ineficiência de alguns serviços em nível dos terminais e porto seco, equipamentos obsoletos, baixo investimento ao longo dos últimos anos e baixa produtividade.

Pushak e Foster (2011) enfatizam que estes congestionamentos favorecem longos atrasos e baixo desempenho, relativamente, a outros portos da África. $\mathrm{O}$ tempo de espera dos contêineres é de 12 dias, ou seja, o dobro do tempo de Durban, na África do Sul. Os autores ainda ressaltam que as taxas de movimentação nos portos angolanos estão entre as mais altas de África.

A utilização das cargas é efetuada via contêiner, confirmando o modal marítimo por todas as empresas e o Incoterm Cost, Insurance and Freight (Custo, Seguro e Frete) é utilizado por $82,36 \%$ da amostra. 
Utilizando uma linha de concordância (pouco relevante, relevante e muito relevante), o questionário tem como objetivo identificar as barreiras organizacionais internas das empresas importadoras, conforme apresentado no quadro 4.

Quadro 4 - Perfil das barreiras internas

\begin{tabular}{|c|c|c|c|c|c|c|c|c|}
\hline \multirow[t]{2}{*}{ AFIRMATIVAS } & \multicolumn{2}{|c|}{$\begin{array}{c}\text { POUCO } \\
\text { RELEVANTE }\end{array}$} & \multicolumn{2}{|c|}{ RELEVANTE } & \multicolumn{2}{|c|}{$\begin{array}{c}\text { MUTTO } \\
\text { RELEVANTE }\end{array}$} & \multirow[t]{2}{*}{$\mathbf{F}$} & \multirow[t]{2}{*}{$\%$} \\
\hline & $\mathbf{F}$ & $\%$ & $\mathbf{F}$ & $\%$ & $\mathbf{F}$ & $\%$ & & \\
\hline Dificuldade e acesso a vendedores em outros paises & 8 & 47,06 & 4 & 23,53 & 5 & 29,41 & 17 & 100,00 \\
\hline Pouca experiência gerencial para a internacionalização & 5 & 29,41 & 6 & 35,29 & 6 & 35,30 & 17 & 100,00 \\
\hline Pouco conhecimento para a internacionalização & 4 & 23,53 & 8 & 47,06 & 5 & 29,41 & 17 & 100,00 \\
\hline Dificuldade em formar parcerias internacionais & 9 & 52,94 & 3 & 17,65 & 5 & 29,41 & 17 & 100,00 \\
\hline Dificuldade em acessar/analisar informações sobre mercados & 1 & 5,88 & 12 & 70,59 & 4 & 23,53 & 17 & 100,00 \\
\hline Falta de um conhecimento maior da cultura de outros paises & 2 & 11,76 & 8 & 47,06 & 7 & 41,18 & 17 & 100,00 \\
\hline Falta de uma estrutura organizacional (dept.de importação) & 6 & 35,30 & 2 & 11,76 & 9 & 52,94 & 17 & 100,00 \\
\hline
\end{tabular}

Fonte: Elaborado pelos autores a partir dos resultados da pesquisa.

Apesar das empresas importadoras estarem presentes no mercado internacional há mais de 10 anos, observa-se uma dificuldade em relação à gestão dos negócios internacionais. Pontos importantes de gerenciamento e prospecção de novos mercados são apontados como entraves internos, como a dificuldade de acessar e analisar informações sobre mercados (70\%), pouco conhecimento do processo de internacionalização (47\%) e falta de conhecimento da cultura de outros países (47\%), por exemplo.

Em termos de estrutura física, ressalta-se a necessidade de uma maior organização processual, em virtude da falta de um departamento de importação estruturado. Em contrapartida, as empresas se sentem mais confortáveis para acessar novos vendedores no mercado externo $(47 \%)$ e formar parcerias internacionais (52\%).

O ambiente externo também oferece desafios para as empresas, uma vez que em virtude da integração econômica e comercial presente na atual conjuntura global, identifica-se o perfil das barreiras externas enfrentadas, conforme é apresentado no quadro 5.

Os principais aspectos apontados se referem à estrutura logística, custos de transporte, ineficiência portuária, barreiras tarifárias, não tarifárias, técnicas, sanitárias e um maior envolvimento dos órgãos intervenientes presentes no processo de despacho aduaneiro de importação. 
Quadro 5 - Perfil das barreiras externas

\begin{tabular}{|c|c|c|c|c|c|c|c|c|}
\hline \multirow[t]{2}{*}{ AFIRMATIVAS } & \multicolumn{2}{|c|}{$\begin{array}{c}\text { POUCO } \\
\text { RELEVANTE }\end{array}$} & \multicolumn{2}{|c|}{ RELEVANTE } & \multicolumn{2}{|c|}{$\begin{array}{c}\text { MUITO } \\
\text { RELEVANTE }\end{array}$} & \multirow[t]{2}{*}{$\mathbf{F}$} & \multirow[t]{2}{*}{$\%$} \\
\hline & $\mathbf{F}$ & $\%$ & $\mathbf{F}$ & $\%$ & $\mathbf{F}$ & $\%$ & & \\
\hline Burocracia alfandegaria & & & 2 & 11,76 & 15 & 88,24 & 17 & 100,00 \\
\hline Custo transporte internacional & & & 3 & 17,65 & 14 & 82,35 & 17 & 100,00 \\
\hline Custos portuários e aeroportuários & & & & & 17 & 100,00 & 17 & 100,00 \\
\hline Barreiras sanitárias & & & 4 & 23,53 & 13 & 76,47 & 17 & 100,00 \\
\hline Barreiras técnicas & & & 3 & 17,65 & 14 & 82,35 & 17 & 100,00 \\
\hline Barreiras tarifarias (imposto importação) & & & 4 & 23,53 & 13 & 76,47 & 17 & 100,00 \\
\hline $\begin{array}{l}\text { Barreiras tarifarias (imposto de consumo, emolumentos gerais, } \\
\text { imposto selo) }\end{array}$ & & & 2 & 11,76 & 15 & 88,24 & 17 & 100,00 \\
\hline Barreiras não tarifarias (cotas, licenciamento) & & & 2 & 11,76 & 14 & 88,24 & 17 & 100,00 \\
\hline Greves na movimentação e liberação das cargas & & & 4 & 23,53 & 13 & 76,47 & 17 & 100,00 \\
\hline Falta de estrutura portuária & & & 2 & 11,76 & 15 & 88,24 & 17 & 100,00 \\
\hline Falta de estrutura aérea & 5 & 29,41 & 2 & 11,76 & 10 & 58,24 & 17 & 100,00 \\
\hline Falta de estrutura rodoviária & & & 3 & 17,65 & 14 & 82,35 & 17 & 100,00 \\
\hline $\begin{array}{l}\text { Falta de dialogo entre os órgãos intervenientes - MINSA,MINCO, } \\
\text { MIT,MINA,MINT }\end{array}$ & 1 & 5,88 & 3 & 17,65 & 13 & 76,47 & 17 & 100,00 \\
\hline Falta de acordos internacionais & 3 & 17,65 & 5 & 29,41 & 9 & 52,94 & 17 & 100,00 \\
\hline Falta de agilidade na liberação aduaneira & & & & & 17 & 100,00 & 17 & 100,00 \\
\hline
\end{tabular}

Fonte: Elaborado pelos autores a partir dos resultados da pesquisa.

As empresas apontaram com muita relevância os principais entraves externos em seus processos de importação, com ênfase para os custos portuários/aeroportuários e falta de agilidade na liberação aduaneira (100\%).

De acordo com o Fattibene et al. (2012), o tempo necessário para a liberação alfandegária dos produtos, que representa uma fração relativamente pequena do lead time total, aumenta significativamente quando as mercadorias passam por inspeção física ou por múltiplas inspeções de diversos agentes, tais como inspeções de padrões de qualidade, órgãos de fiscalização de saúde ou agências sanitárias e fitossanitárias. Tais procedimentos são importantes; porém, devem ser gerenciados de forma eficiente, proporcionando segurança e rapidez na liberação aduaneira, a fim de não onerar o importador com custos extras de armazenagem, decorrentes de uma sobre-estadia na zona primária.

Ainda, a partir da análise, pode ser observado que $88 \%$ das empresas entrevistadas sustentam que as barreiras protecionistas, especificamente as de cunho tarifário, contribuem para o baixo índice de desempenho das empresas, caracterizado como um fator catalisador de prejuízo. Por outro lado, aponta-se também a burocratização e a falta de estrutura portuária face a falta de agilidade e carência de gestão portuária. Nesse ponto, Figueiredo, Fleury e Wanke (2003) afirmam que um porto eficaz deve minimizar a permanência do navio, ou seja, a soma da atracação, tempo de operação e liberação do navio, proporcionando para ambos, armador e cliente, redução de custos logísticos. 
Essa situação de ineficiência na gestão portuária e a necessidade de uma estrutura competitiva também é uma realidade brasileira. De acordo com o Relatório n. 48 do Instituto de Pesquisa Econômica Aplicada - IPEA (2010), na série "Eixos do Desenvolvimento Brasileiro", surgem desafios e ineficiência relacionados com a burocracia na liberação de cargas, greves, custos de estiva, capatazia e praticagem, e a restrição de horário de funcionamento das aduanas, interferindo diretamente na liberação das mercadorias. Os dados também apontam, negativamente, para a infraestrutura portuária, pois $49,1 \%$ das empresas exportadoras brasileiras consideram a mais deficiente entre as etapas pós-produtivas, interferindo em $88 \%$ das empresas no escoamento da produção.

Por fim, um problema muito citado quando tratamos de atraso ou paralisação de obras em geral e, em especial, as portuárias, referese à questão das licenças ambientais, cuja demora no processo de concessão é visto como um entrave para empreiteiras e empresários. Todavia, embora seja inegável a necessidade de uma gestão mais eficiente nos órgãos competentes, há que se considerar que grande parte desses atrasos se deve, de fato, à ocorrência de projetos mal elaborados (IPEA, 2010, p. 14).

Nesse sentido, políticas públicas e um direcionamento governamental para compor um programa de estrutura nacional são importantes, a fim de que o setor público, aliado à iniciativa privada, possa organizar esforços para uma maior competitividade do país no mercado global.

De acordo como quadro 6 , no que tange à melhoria, cerca de $90 \%$ das empresas entrevistadas indicaram que os elementos preponderantes para aperfeiçoar o sistema logístico, referem-se à redução do custo do transporte e porto, fator crucial para a estabilização da competitividade das empresas.

Fica evidente, também, a melhoria na infraestrutura rodoviária, considerada um elemento relevante, quando se coloca em questão o sistema logístico, consequente ao modal e os sistemas de entrega. 
Quadro 6 - Perspectivas de fomento as importações

\begin{tabular}{|c|c|c|c|c|c|c|c|c|}
\hline \multirow[t]{2}{*}{ AFIRMATIVAS } & \multicolumn{2}{|c|}{$\begin{array}{c}\text { POUCO } \\
\text { RELEVANTE }\end{array}$} & \multicolumn{2}{|c|}{ RELEVANTE } & \multicolumn{2}{|c|}{$\begin{array}{c}\text { MUITO } \\
\text { RELEVANTE }\end{array}$} & \multirow[t]{2}{*}{$\mathbf{F}$} & \multirow[t]{2}{*}{$\%$} \\
\hline & $\mathbf{F}$ & $\%$ & $\mathbf{F}$ & $\%$ & $\mathbf{F}$ & $\%$ & & \\
\hline Desoneração tributaria & 2 & 11,76 & 7 & 41,18 & 8 & 47,06 & 17 & 100,00 \\
\hline Informação comercial sobre mercados externos & & & 5 & 29,42 & 12 & 70,58 & 17 & 100,00 \\
\hline Desburocratização da atividade importadora & & & 4 & 23,53 & 13 & 76,47 & 17 & 100,00 \\
\hline Redução de custos de transporte e portos & & & 2 & 17,76 & 15 & 88,24 & 17 & 100,00 \\
\hline Melhoria na infraestrutura portuária & 2 & 11,76 & 1 & 5,88 & 14 & 82,36 & 17 & 100,00 \\
\hline Melhoria na infraestrutura aeroportuária & 1 & 5,88 & 4 & 23,53 & 12 & 70,59 & 17 & 100,00 \\
\hline Melhoria na infraestrutura rodoviária & & & 3 & 17,65 & 15 & 88,24 & 17 & 100,00 \\
\hline Eliminação/ redução das barreiras comerciais em Angola & 4 & 23,53 & 5 & 29,41 & 8 & 47,06 & 17 & 100,00 \\
\hline Capacitação em comercio exterior & 1 & 5,88 & 3 & 17,65 & 13 & 76,47 & 17 & 100,00 \\
\hline Ampliação dos acordos intemacionais de comércio & & & 4 & 23,53 & 13 & 76,47 & 17 & 100,00 \\
\hline
\end{tabular}

Fonte: Elaborado pelos autores a partir dos resultados da pesquisa.

Também no contexto brasileiro, é importante mencionar que, decorrente dos gargalos logísticos na operação marítima brasileira e a necessidade de dinamizar a movimentação das mercadorias, potencializando os portos, o governo federal implementou a lei n. 12.815 (BRASIL, 2013) em 5 de junho de 2013.

A nova Lei dos Portos (lei 12.815/2013) estabeleceu um novo arranjo institucional para o setor portuário, com atribuições bem delineadas para cada um dos atores-chave. Cabe a Secretaria de Portos o planejamento, a elaboração do Plano Nacional de Logística Portuária - PNLP, dos Master Plans e do Plano Geral de Outorgas - PGO, além da aprovação dos planos de desenvolvimento e zoneamento - PDZs de cada porto. A SEP também é a responsável pelas outorgas, concessões, autorizações, arrendamentos e delegações (SEP/PR, 2015, p. 1).

Esse planejamento via planos estruturais e investimentos foram no âmbito dos portos, estipulados para fortalecer a infraestrutura necessária para o escoamento da produção nacional, bem como minimizar os gargalos na nacionalização de produtos oriundos do mercado internacional.

Por fim, o quadro 7 apresenta de forma sintetizada os principais resultados da pesquisa. 
Quadro 7-Síntese dos principais resultados

\begin{tabular}{|l|l|}
\hline \multicolumn{1}{|c|}{ ASPECTOS } & \multicolumn{1}{|c|}{ CARACTERISTICAS } \\
\hline Perfil empresarial & $\begin{array}{l}\text { Destacam-se importadores, predominantemente, no setor alimenticio e também nos setores } \\
\text { cerâmicos, máquinas e equipamentos, metalúrgico, produtos plásticos, vestuário, quimico, } \\
\text { autopeças, concessionária, construção civil e produtos elétricos. Com ênfase no porte médio e } \\
\text { com negociações diretas com o mercado internacional, as importadoras localizam-se em maior } \\
\text { número em Luanda, com capital essencialmente nacional e com experiência acima de } 10 \text { anos no } \\
\text { mercado externo. }\end{array}$ \\
\hline Perfil logistico & $\begin{array}{l}\text { As importadoras nacionalizam suas mercadorias via Porto de Luanda, utilizando a carga } \\
\text { conteinerizada e o Incoterm Custo, Seguro e Frete (CIF). }\end{array}$ \\
\hline Barreiras internas & $\begin{array}{l}\text { Necessidade de um desenvolvimento gerencial do processo de internacionalização, falta de } \\
\text { conhecimento da cultura de outros paises e a necessidade de uma estrutura organizacional } \\
\text { voltada para a prática importadora. }\end{array}$ \\
\hline Barreiras externas & $\begin{array}{l}\text { Burocracia alfandegária, falta de estrutura portuária, precariedade na liberação aduaneira e } \\
\text { custos logisticos. }\end{array}$ \\
\hline Politicas para fomento as importações & $\begin{array}{l}\text { Desburocratização dos processos aduaneiros, redução de custos portuários, infraestrutura } \\
\text { portuária e rodoviária, capacitação em comércio exterior e aumento de acordos internacionais. }\end{array}$ \\
\hline
\end{tabular}

Fonte: Elaborado pelos autores a partir dos resultados da pesquisa.

\section{CONSIDERAÇÕES FINAIS}

A infraestrutura logística e a integração dos modais de transporte são fatores estratégicos para a competitividade de uma nação perante o mercado global. As políticas públicas e a participação da iniciativa privada, nesse contexto, são de fundamental importância, uma vez que o planejamento compartilhado e um programa nacional de desenvolvimento somente têm a favorecer toda a cadeia logística que utiliza as estruturas rodoviárias, ferroviárias, aéreas e portuárias para o escoamento da produção, direcionados ao mercado nacional ou internacional.

Todas as mercadorias destinadas ou oriundas do mercado externo sofreram um processo de despacho aduaneiro de exportação ou importação, a fim de que a autoridade aduaneira possa verificar se todos os requisitos administrativos, sanitários ou fiscais foram cumpridos de acordo com as normas e regulamentos existentes em cada nação.

Os portos, as rodovias e as ferrovias são considerados pontos de ligação que possibilitam o transporte de cargas entre importadores e exportadores. Dessa forma, o trabalho procurou identificar as barreiras internas e externas das empresas importadoras de Angola no processo de despacho aduaneiro de importação. 
Sugere-se que, com relação à falta de informações em Angola, desenvolva-se um portal estabelecido pelos órgãos inerentes ao comércio exterior angolano, contendo a prospecção de mercado e informações a ele vinculadas. Um bom exemplo brasileiro são os portais do Ministério do Desenvolvimento Indústria e Comércio Exterior (MDIC), do Ministério das Relações Exteriores (MRE) e da própria Receita Federal do Brasil (RFB), pois agrupam informações e sistemas para a análise do comércio internacional (Sistema ALICEWeb), totalmente disponível e de domínio público.

Recomenda-se para o ramo empresarial angolano a utilização do Supply Chain Management, uma vez que existe demanda sobre os sistemas logísticos e uma gestão eficaz de suprimentos para aperfeiçoar o processo e reduzir custos logísticos provenientes da atividade exportadora e importadora.

Acredita-se que o trabalho cumpriu seu papel, a partir da discussão e explicitação das barreiras internas e externas das empresas importadoras de Angola, proporcionando uma integração de conhecimento. Angola é uma nação com muitas variáveis, que ainda não tiveram pesquisas aprofundadas, necessitando de maior investigação por parte do poder público e de entidades privadas para obter mais informações a respeito de sua história, sociedade, economia e produção, proporcionando, assim, condições sustentáveis para um futuro com maiores oportunidades.

\section{REFERÊNCIAS}

ALVES, M. Como escrever tese e monografia. São Paulo: Campus 2006.

BRASIL. Lei n. 12.815 de 5 de junho de 2013. Dispõe sobre a exploração direta e indireta pela União de portos e instalações portuárias e sobre as atividades desempenhadas pelos operadores portuários; altera as Leis n. 5.025, de 10 de junho de 1966, 10.233, de 5 de junho de 2001, 10.683, de 28 de maio de 2003, 9.719, de 27 de novembro de 1998, e 8.213, de 24 de julho de 1991; revoga as Leis n. 8.630, de 25 de fevereiro de 1993, e 11.610, de 12 de dezembro de 2007, e dispositivos das leis n. 11.314, de 3 de julho de 2006, e n. 11.518, de 5 de setembro de 2007; e dá outras providências. Disponível em: < http://www.planalto.gov.br/ ccivil_03/_ato2011-2014/2013/Lei/L12815.htm>. Acesso em: 12 jul. 2014.

BRASIL. Ministério das Relações Exterior. MRE. 2014. Angola comércio exterior. Disponível em: <http://www.brasilglobalnet.gov.br/ARQUIVOS/ IndicadoresEconomicos/INDAngola.pdf>. Acesso em: 30 mar. 2015. 
BRASIL. Ministério das Relações Exterior. MRE. 2015. Angola comércio exterior. Disponível em: <http://www.brasilexport.gov.br/sites/default/files/publicacoes/ indicadoresEconomicos/INDAngola.pdf>. Acesso em: 30 mar. 2015.

BRASIL. Ministério da Fazenda. Receita Federal do Brasil. RFB. 2015. Despacho aduaneiro de importação. Disponível em:<http://www.receita.fazenda.gov.br/ aduana/procaduexpimp/despaduimport.htm>. Aceso em: 25 mar. 2015.

CERVO, A. L.; BERVIAN, P. A.; SILVA, R. da. Metodologia científica. 6. ed. São Paulo: Pearson Prentice Hall, 2007.

CNCA. Conselho Nacional dos Carregadores de Angola. Institucional. Produtos mais importados 2013. Disponível em: <http://www.cnc-angola.com>. Acesso em: 24 maio 2014.

DILOLWA, C. R. Contribuição à história econômica de Angola. 2. ed. Luanda: Nzila, 2000

DOWBOR, L. O Brasil na economia internacional. São Paulo: Atlas, 2012.

FATTIBENE, M.; et al. Desempenho logístico do Brasil: estudo dos indicadores alfândega e pontualidade. In: XXXII Encontro Nacional de Engenharia de Produção. Desenvolvimento sustentável e responsabilidade social: as contribuições da Engenharia da Produção. Bento Gonçalves, RS, Brasil, 15 a 18 de outubro de 2012. Disponível em: <http://www.abepro.org.br/biblioteca/ENEGEP2012_TN_ STP_157_918_20187.pdf>. Acesso em: 20 mar. 2015.

FIGUEIREDO, K. F.; FLEURY, P. F; WANKE, P. Logística e gerenciamento da cadeia de suprimentos: planejamento do fluxo de produtos e dos recursos. São Paulo: Atlas, 2003.

IPEA. Instituto de Pesquisa Econômica Aplicada. Portos brasileiros: diagnóstico, políticas e perspectivas. Série eixos do desenvolvimento brasileiro. Comunicados do Ipea n. 48, 2010.Disponível em: <http://www.ipea.gov.br/portal/images/ stories/PDFs/comunicado/100517_comunicadoipea48.pdf>. Acesso em: 29 mar. 2015.

MARINI, L. Análise comparativa entre a utilização do regime de embarque antecipado versus o despacho aduaneiro normal nas exportações via porto de Itajaí - S.2010. 90 f. Trabalho de Conclusão de Curso (Graduação em administração com hab. em Comércio Exterior) - Universidade do Extremo Sul Catarinense, Criciúma. 
MINCO. Ministério do Comércio. Institucional. 2014. Disponível em: <http://www. minco.gov.ao>. Acesso em: 28 abr. 2014.

MINERVINI, N. O exportador. 3. ed. São Paulo: Makron Books, 2001.

MORINI, C.; SIMÕES, R. C. F.; DAINEZ, V. I. Manual de comércio exterior. 2. ed. Campinas: Alínea, 2012.

PUSHAK, N.; FOSTER, V. AICID - Angola relatório nacional infraestrutura em Angola: Uma perspectiva Continental. Portos de Angola. Disponível em: <http:// siteresources.worldbank.org/ANGOLAEXTN/Resources/AICD-Angola_Country_ Report.pdf>. Acesso em: 27 set. 2014.

SEP/PR. Secretaria Especial dos Portos da Presidência da República. Planejamento portuário nacional. Brasília. 2015. Disponível em: <http://www.portosdobrasil. gov.br/assuntos-1/pnpl>. Disponível em: 15 fev. 2015.

REVISTA DE MARINHA. Tempo de espera no porto de Luanda passou de 80 a 10 dias. 2009. Disponívelem:<http://www.revistademarinha.com/index.php?option=com_ content $\&$ view $=$ article $\& i d=1304$ : porto-luanda $\&$ catid $=101$ : actualidadenacional\&Itemid=290>. Acesso em: 18 set. 2014.

ROESCH, S. M. A. Projetos de estágios e de pesquisa em administração: guia para estágios, trabalhos de conclusão, dissertações e estudos de caso. 3. ed. São Paulo: Atlas, 2007.

VERGARA, S. P. Projetos e relatórios de pesquisa em administração. 11. ed. São Paulo: Atlas, 2009.

ZILLI, J. C.; LINO, C. L. F.; DAL TOÉ, R. A. Análise comparativa do processo de despacho aduaneiro de importação de mercadorias no porto de Luanda/Angola versus do porto de Itajaí/Brasil. 2013. In: XXIV ENANGRAD. Encontro Nacional dos Cursos de Graduação em Administração. Florianópolis. Disponível em: <http:// www.enangrad.org.br/anais2013/_resources/artigos/gol/03.pdf>. Acesso em: 20 mar. 2015. 